\title{
ENSINO TÉCNICO PROFISSIONALIZANTE - ESTUDO DE CASO: UMA PROPOSTA DE CURSO TÉCNICO DA REDE E-TEC BRASIL
}

\author{
Adelson de Paula Silva ${ }^{1}$ \\ Viviane Sartori ${ }^{2}$
}

\section{RESUMO}

A evolução das Tecnologias de Informação e Comunicação (TIC) potencializou a Educação a Distância (EaD). O programa Rede e-Tec Brasil fez uso desses aportes tecnológicos ofertando cursos técnicos de nível médio, mudando o perfil da educação profissionalizante brasileira. $\mathrm{O}$ objetivo deste estudo é proporcionar um novo olhar para a educação profissional brasileira a partir da EaD e do Programa da Rede e-Tec Brasil, apresentando o curso de formação de Técnico de Informática para Internet do programa da Rede e-Tec Brasil do Centro Federal de Educação Tecnológica de Minas Gerais (CEFET$M G$ ). A presente pesquisa é de natureza aplicada, exploratória, descritiva, bibliográfica, documental, estudo de caso e quali-quantitativa. Os resultados apontam que os cursos oferecidos na modalidade EaD, promovidos no âmbito da Rede e-Tec, organizados em propostas de ensino estruturadas, contribuem para o crescimento da educação técnica profissional brasileira.

Palavras-chave: Ensino Técnico Profissional; Rede e-Tec; Proposta de Ensino na EaD.

\section{TECHNICAL VOCATIONAL EDUCATION - CASE STUDY: A PROPOSAL OF TECHNICAL COURSE OF E-TEC BRAZIL NETWORK}

\begin{abstract}
The evolution of information and communication technologies (ICT) has potentialized the Distance Education. The program e-Tec Brazil Network made use of these technological contributions offering Secondary Technical Education Courses, changing the profile of the Brazilian professionalizing education. The aim of this study is to provide a new look for the Brazilian professional education from the Distance Education and Program e-Tec Brazil Network, the course for preparation of computer Technician for internet of the program e-Tec Brazil Network of the Centro Federal de Educação Tecnológica de Minas Gerais (CEFET-MG). This research has applied nature, exploratory, descriptive, bibliographical, documentary, case study and qualitative and quantitative classification. The results
\end{abstract}

\footnotetext{
${ }^{1}$ Lotado no Departamento de Computação do CEFET-MG. Doutor na área de Ensino Mestre em Tecnologia. Possui experiência na área de Ciência da Computação, com ênfase em Infraestrutura de Redes, desenvolvimento de soluções na área de Tecnologia da Informação atuando principalmente nos seguintes segmentos: Educação Empreendedora, Inovação no Ensino Técnico, Ensino Técnico e Tecnológico, Projeto de Redes de Comunicação, Implementação de solução para desenvolvimento de ambientes de TI, Instalação de Aplicações para à área de Gestão Documental e ensino a distância. Desenvolve pesquisas na área de educação científica e empreendedora, ensino à distância, tecnologias de ensino e tecnologia da informação. E-mail: <adelson@decom.cefetmg.br> ${ }^{2}$ Graduada em Pedagogia pela Universidade Estadual de Maringá (UEM-1994). Possui habilitação em Supervisão Escolar e Administração Escolar pela Universidade Bandeirante de São Paulo (UNIBAN-2000). Mestre em Engenharia e Gestão do Conhecimento da Universidade Federal de Santa Catarina (UFSC-2012) e atualmente doutoranda do mesmo programa. Publicou trabalhos em anais de eventos científicos nacionais e internacionais e participou de produção em capítulos de livros direcionado à área de Gestão do Conhecimento e Educação. Tem 20 anos de experiência na área da educação presencial e a distância, atuando como docente de educação infantil e ensino fundamental, na coordenação pedagógica e em cursos de Educação na modalidade a Distância. E-mail: <vivi.sartori19@gmail.com>
} 
show that the courses offered in distance education mode promoted within the e-Tec Network, organized in structured educational proposals, contribute to the growth of Brazilian professional technical education.

Keywords: Technical Vocational Education; e-Tec Network; Proposal for Education in Distance Education.

\section{ENSEÑANZA PROFISIONAL TÉCNICA - ESTUDIO DE CASO: UNA PROPUESTA DE CURSO TÉCNICO DE LA RED E-TEC BRASIL}

\section{RESUMEN}

La evolución de las Tecnologías de Información y Comunicación (TIC) ha potencializado la Educación a Distancia (EaD). El programa Red e-Tec Brasil hice uso de eses aportes tecnológicos ofreciendo cursos técnicos de nivel medio, cambiando el perfil de la educación profesional brasileña. El objetivo de este estudio es proporcionar una nueva mirada para la educación profesional brasileña desde la EaD y del Programa da Red e-Tec Brasil, presentando el curso de formación de Técnico de Informática para Internet del programa de la Red e-Tec Brasil del Centro Federal de Educación Tecnológica de Minas Gerais (CEFET-MG). Esta investigación tiene naturaleza aplicada, exploratoria, descriptiva, bibliográfica, documental, estudio de caso y cualitativa y cuantitativa. Los resultados apuntan que los cursos ofrecidos en la modalidad EaD promovidos en el ámbito de la Red e-Tec, organizados en propuestas de enseñanza estructuradas, contribuyen para el crecimiento de la educación técnica profesional brasileña.

Palabras-clave: Enseñanza Técnico Profesional; Red e-Tec; Propuesta de Enseñanza en la EaD.

\section{Introdução}

O ensino técnico profissionalizante brasileiro tem um histórico com muitas mudanças. Desde suas primeiras ações até o presente momento, a educação profissional brasileira passou por muitos avanços e desdobramentos visando a atender às necessidades de uma sociedade em transformação. Ações estas que delinearam nova legislação, que foi elaborada, ajustada e cancelada. Escolas técnicas, secundárias e institutos foram criados e/ou adaptados para atender a demanda iniciada, principalmente após a segunda guerra mundial.

Após varias décadas de ações consideradas positivas e negativas, em 2007 a educação profissional brasileira teve um grande avanço com a criação dos Institutos Federais de Educação Tecnológica (IFET) e com o trabalho dos CEFET, que têm ofertado cursos profissionalizantes, principalmente de nível médio e pós-médio. 
Outros fatores têm colaborado para alavancar este processo de forma significativa na qualidade e abrangência deste segmento, a evolução da Educação a Distância (EaD) e a criação de dois grandes programas desta modalidade: o programa Universidade Aberta do Brasil (UAB), que oferta cursos de graduação e pós-graduação para formação de professores e gestores públicos; e o programa Rede e-Tec Brasil, com foco em cursos técnicos de nível médio.

Os cursos previstos no programa da Rede e-Tec Brasil são desenvolvidos na modalidade subsequente e concomitância externa, isto é, destinados a estudantes que concluíram ou que estão cursando o Ensino Médio, com o objetivo de formar técnicos de nível médio, preparando, assim, os estudantes para atividades profissionais.

O caso apresentado neste artigo é uma experiência de ensino dentro do projeto de EaD promovido pelo Centro Federal de Educação Tecnológica de Minas Gerais (CEFET-MG), vinculado a Rede e-Tec, que propõe a formação de Técnicos em Informática para Internet, com o objetivo de contribuir para ampliação da oferta e democratização do acesso a cursos técnicos de nível médio, públicos e gratuitos para o interior do estado de Minas Gerais e para a periferia da área metropolitana de Belo Horizonte.

Este projeto foi iniciado em 2010 com a oferta de cursos técnicos de nível médio na modalidade a distância, junto às instituições públicas de ensino municipais e estaduais funcionando em rede, como estabelecimentos de apoio presencial (polos).

\section{Ensino Técnico Profissionalizante - Contexto Histórico}

No início do século XX, o Brasil inicia seu processo de industrialização, alterando seu modelo sócio-produtivo de agrário exportador para industrial (CUNHA, 2000). Esse cenário que vai se desenhando demandou diversas ações ao governo, incluindo, em 1909, a criação de instituições denominadas Escolas de Aprendizes Artífices que, devido a sua importância e influência, foram a origem e referência do atual modelo de ensino profissional brasileiro. Essas escolas tiveram uma legislação específica, que as diferenciava das demais instituições de ofícios, inclusive das mantidas pelo próprio governo federal. 
Em 1918 estes cursos passaram a exigir o curso primário para a sua frequência, e eram oferecidos em período diurno, deixando o período noturno para cursos de aperfeiçoamento para os operários que já se encontrassem no mercado de trabalho (CUNHA, 2000).

Desde suas primeiras ações até o presente momento, a educação profissional brasileira passou por diversas alterações, atendendo a diferentes demandas da sociedade. Segundo Cunha (2000), um aspecto significativo das escolas de aprendizes artífices diz respeito aos cursos comuns a estas escolas, que pretendiam capacitar estudantes em marcenaria, alfaiataria e sapataria, cursos estes de características mais artesanais do que propriamente manufatureiras.

No período de 1930 a 1935, quando Anísio Teixeira foi diretor de Educação do Distrito Federal, foram criadas escolas técnicas nas quais o ensino profissional passou para o pós-primário, em uma primeira tentativa de integração entre o sistema geral de ensino e o profissional.

As Escolas de Aprendizes Artífices existiram até 1937, quando foram transformadas em Liceus Profissionais, destinados ao ensino profissional de todos os ramos e graus (BRASIL, 2015). Desde esta época, o Brasil convive com dois modelos de escola propostos para públicos diferenciados, sendo um o ensino profissional - destinado às classes menos favorecidas; e outro, o ensino propedêutico - destinado aos alunos em condições de seguir estudos no nível superior.

Em um segundo momento, com a criação, em 1942, do Serviço Nacional de Aprendizagem Industrial (SENAI), e logo em seguida, em 1946, com a criação do Serviço Nacional de Aprendizagem Comercial (SENAC) e outras instituições que compõe o hoje chamado Sistema S, o próprio ensino profissional passa a ser dicotomizado em dois sistemas independentes, um deles originado da Escola de Aprendizes e Artífices, que continua a ser mantido pelo governo segundo a ideologia assistencialista, e outro, a ser organizado e mantido pelo setor produtivo industrial (indústrias e sindicatos).

Em 1942 foram implantadas as chamadas leis orgânicas do ensino profissional, provocando uma grande reforma no sistema de ensino profissional brasileiro. Esta reforma 
estabeleceu um ensino mais propriamente industrial, deslocando a formação profissional do curso primário para o primeiro ciclo do secundário.

A Lei Orgânica do Ensino Industrial previa quatro tipos de curso no primeiro ciclo do secundário: industrial básico (ensino de ofícios), aprendizagem (para operários das indústrias), mestria (formação de mestres) e artesanal (ensino rudimentar de ofícios). No segundo ciclo foram previstos cursos técnicos e pedagógicos, estes destinados à formação de professores e gestores do ensino profissional. Os cursos de mestria e artesanal tiveram resultados quase nulos, sobressaindo as escolas de cursos industriais básicos.

Esta reforma transformou, também, os Liceus Industriais criados em 1937 em Escolas Técnicas. Mais tarde, outros serviços desse tipo foram sendo criados, constituindo um sistema de ensino profissional gerido por organizações ligadas aos setores profissionais.

A divisão em ciclos implantada pela lei orgânica do ensino industrial não funcionou, prestigiando o SENAI em detrimento das escolas profissionais do sistema estatal. Em 1959, a formação de operários fica efetivamente a cargo do SENAI, enquanto o ensino técnico, em novos moldes, ficou a cargo das Escolas Técnicas Federais.

Em 1961 foi promulgada a primeira Lei de Diretrizes e Bases da Educação (LDB), e o sistema de ensino criado foi dividido em: Ensino Primário, Ensino de grau Médio e Educação de grau Superior, sendo o ensino de grau médio dividido em: 1ㅇ ciclo - ginasial e de 20 ciclo colegial (secundário, técnico e de formação de professores para o ensino primário e préprimário).

Em 1971 a Lei 5.692 transformou, compulsoriamente, todos os cursos de segundo grau (antigo ensino de grau médio) em cursos profissionalizantes, destinados a formar técnicos e auxiliares técnicos, seguindo o modelo de sucesso das Escolas Técnicas, sob o argumento de que havia falta desses profissionais para o desenvolvimento do país. Como não obteve o sucesso esperado, logo, em 1982, precisou ser revogada, através do decreto 7.044

Em 1978, as escolas técnicas do Paraná, Minas Gerais e Rio de Janeiro são transformadas em Centros Federais de Educação Tecnológica (CEFET). As demais escolas, bem como as Escolas Agrotécnicas Federais, passam gradativamente a serem transformadas em CEFET a partir de 1999, processo este denominado de cefetização, que faz parte da ampliação do sistema de ensino específico para a educação profissional. 
Em 1996 é promulgada uma nova Lei de Diretrizes e Bases da Educação, que trouxe alterações no sistema de ensino sem, contudo, acabar com a dualidade entre ensino geral e profissional, que foi acirrada pelo decreto 2.208 de 1997 , que sedimenta mais ainda esta ideia. Este decreto foi revogado pela Lei $n^{\circ} .5 .184$ de 25 de julho de 2004, que restaurou a possibilidade de integração entre o ensino geral e o profissional no âmbito do Ensino Médio, mantendo, também, as formas concomitante e subsequente.

Em 2005, em decorrência das possibilidades desta última lei, das três instituições CEFET, a do Paraná foi transformada em Universidade Tecnológica.

Em 2007 foram criados os Institutos Federais de Educação Tecnológica, a partir dos antigos CEFET ainda existentes, exceto de Minas Gerais e Rio de Janeiro. Estes ainda são Centros Federais por não aceitar a transformação em Instituto de Educação Tecnológica e ficaram entre os Institutos e Universidades, constituindo elementos restantes de um sistema em extinção.

Nos anos seguintes os Institutos Federais assumiram a oferta de cursos profissionalizantes, principalmente de nível médio e pós-médio, sendo também os que mais intensamente participam da Rede e-Tec Brasil.

\section{Educação a Distância}

A Educação a Distância (EaD) é uma das modalidades educacionais que vem se destacando devido às suas características de abrangência, flexibilidade, liberdade e acesso. É um rico instrumento capaz de trocar e articular conhecimentos e informações entre as mais diversas comunidades virtuais de aprendizagem (MOORE; KEARSLEY, 1996).

Esta modalidade caracteriza-se a partir do planejamento do aprendizado, que geralmente acontece em diferentes locais, a partir do ensino e dos resultados provenientes de técnicas de design do curso, técnicas instrucionais, métodos de comunicação eletrônica, da organização e arranjos administrativos e da interação entre os estudantes (LIBÂNEO, 1992; CUNHA, 2000). 
Brito (2010) corrobora com a ideia da EaD como um processo de ensinoaprendizagem que faz uso da tecnologia como elemento mediador. Professores e estudantes geralmente não estão juntos, estão separados física e/ou temporalmente; entretanto, podem estar conectados pela tecnologia ou fazer uso de correio, rádio, TV, vídeo, CD-ROM, telefone, etc.

Historicamente, a EaD teve seus primeiros passos com a iniciativa de Caleb Philips, em 1728, na Gazette of Boston, Estados Unidos da América (EUA), que encaminhava semanalmente lições para estudantes previamente inscritos. Após essa iniciativa, atividades semelhantes foram surgindo gradativamente e se desenvolvendo por gerações.

Após a Primeira Guerra Mundial houve um avanço significativo nessa modalidade educativa, pois havia, então, uma demanda social por formação educacional.

Oxford e Cambridge, na Grã-Bretanha, Chicago e Wisconsin criam seus cursos, assim como na Alemanha, com Fritz Reinhardt, que funda a Escola Alemã por correspondência, em 1924 (MORAN, 2002).

$\mathrm{O}$ advento do rádio, no início do século $\mathrm{XX}$, possibilitou a ampliação da $\mathrm{EaD}$ caracterizando, assim, uma nova geração. A primeira autorização para o funcionamento de uma emissora educacional foi concedida pelo governo federal norte-americano, a Latter Day Saints, pertencente à University of Salt Lake City.

Em 1928, a British Broadcasting Corporation (BBC) inicia cursos de educação de adultos usando o rádio. Segundo Nunes (2009), essa tecnologia de comunicação foi empregada por diversos países, inclusive no Brasil a partir de 1930.

O grande impulso à EaD aconteceu na década de 1960, na Europa, alastrando-se pelos cinco continentes, chegando a todos os níveis educacionais e beneficiando milhões de estudantes por todo o mundo.

Essa geração caracteriza-se pelo uso de variadas tecnologias sem utilizar computadores para divulgar os conteúdos. As fitas de áudio, televisão, fitas de vídeo, fax e papel impresso eram as mídias então usadas (MOORE; KEARSLEY, 2007).

A próxima geração avança acrescentando novas tecnologias, como o uso de computadores e dos recursos que este passou a oferecer, como correio eletrônico, chat, CD, internet e videoconferência. 
Um novo avanço aconteceu com o advento da banda larga (internet de alta velocidade), que contribuiu significativamente para o desenvolvimento da EaD, que agora está inserida em uma sociedade onde a informação e o conhecimento começam a ter grande valor socioeconômico.

Uma nova geração da EaD organizou-se a partir da estrutura que foi edificada com o surgimento da internet, apropriando-se, inicialmente, de uma tecnologia chamada de world wide web, que possibilitou as classes virtuais on-line (BRITO, 2010).

Estes avanços trouxeram elementos inovadores para a aprendizagem, pois se caracterizam pela disposição de textos, áudio e vídeo em uma mesma plataforma de comunicação, possibilitando, assim, a transposição das barreiras geográficas e de comunicação. Como tratado por Hijazi et al., (2003), a EaD está evoluindo e gerando inovação graças ao avanço extraordinário da tecnologia.

\subsection{Educação a Distância}

No Brasil, antes mesmo de 1900 já era possível estudar sem necessitar estar presente em bancos escolares. Jornais que circulavam na cidade do Rio de Janeiro ofereciam cursos profissionalizantes por correspondência ministrados por professores particulares.

Já na década de 1930, a Marinha realiza cursos via correspondência, e na década seguinte surge o Instituto Universal Brasileiro, que fortalece a EaD expandindo a formação profissional de nível elementar e médio, através de material impresso (MOREIRA, et al., 2010).

Após a Segunda Guerra Mundial houve grandes modificações econômicas e sociais que possibilitaram uma revolução. Essa revolução é chamada, por alguns estudiosos, de tecnocientífica, ou seja, a integração física entre ciência e produção que atingiu todos os segmentos da sociedade, de empresas a indústrias, de pesquisadores a pessoas comuns (CUNHA, 2000).

A EaD, no Brasil, tem sua legitimação consolidada na Lei no 9.394/96, sendo regulamentada pelo Decreto no 5.622 de dezembro de 2005 e pela Portaria Ministerial no 4.361/2004 (BRITO, 2010). 
Foi reconhecida como modalidade educacional tendo, como um dos seus princípios, a obrigatoriedade de momentos presenciais em atividades como avaliação, estágios, defesas de trabalhos e atividades laboratoriais (CUNHA, 1998).

Segundo a ABED (2015), nos últimos anos, o Brasil teve um crescimento de mais de 300\% na EaD. O credenciamento de instituições para ofertar ensino superior a distância aumenta vertiginosamente ano a ano. Esse crescimento possibilita a inclusão de regiões desfavorecidas, estimulando mudanças sociais e, consequentemente, o crescimento global e local (BRITO, 2010).

As transformações sociais, a necessidade de formação continuada e os avanços das Tecnologias de Informação e Comunicação (TIC) proporcionaram mudanças significativas nos paradigmas educacionais. A EaD, antes vista com descrédito e associada à opção de segunda categoria para os indivíduos excluídos do sistema convencional de educação, hoje apresentase como solução para uma nova sociedade (VOIGT, 2007). Esta se transforma em uma modalidade de ensino inquestionável, capaz de minimizar essa exclusão, pois se constitui em uma ferramenta democrática, inclusiva, que aumenta as chances de inclusão de indivíduos no universo de saber epistemológico, independentemente de suas origens (BRITO, 2010).

\section{Rede e-Tec Brasil}

No intuito de expandir o ensino técnico profissional de nível médio e o ensino superior e, consequentemente, estimular a EAD no país, o governo federal brasileiro lançou dois grandes programas, sendo um deles destinado a viabilizar cursos de graduação e pósgraduação para formação de professores e gestores públicos, o programa Universidade Aberta do Brasil (UAB), criado por meio do Decreto 5.800 de 8 de junho de 2006, e outro para a oferta de cursos técnicos de nível médio, o programa Escola Técnica Aberta do Brasil -Rede e-Tec Brasil, com origem no Decreto 6.301 de 12 de dezembro de 2007.

A Rede e-Tec publicou seu primeiro edital em dezembro de 2007 e, durante o ano seguinte, foi organizado o sistema de forma a viabilizar a oferta de cursos técnicos.

Os cursos foram organizados em conformidade com o Catálogo Nacional dos Cursos Técnicos (CNCT, 2014), documento que orienta e estabelece as condições de oferta de 
cursos técnicos no país. Os cursos previstos no programa são do tipo subsequente, isto é, destinados a estudantes que concluíram o Ensino Médio, com objetivo de formar técnicos de nível médio, preparando, assim, os estudantes para atividades profissionais.

A formação de técnicos de nível médio no Brasil admite três possibilidades: formação integrada, unindo no mesmo curso o Ensino Médio e o ensino profissional; formação concomitante, onde o ensino profissional é realizado em paralelo com o Ensino Médio, em cursos distintos; e a formação subsequente, onde o curso do ensino profissional ocorre após a conclusão do Ensino Médio.

Pelas características da legislação, os cursos técnicos subsequentes têm duração mínima a partir de 800 horas em um ano letivo. Em geral, os cursos ofertados têm carga horária entre 800 e 1600 horas distribuídas entre 1 e 2 anos.

O modelo adotado compreende as atividades letivas concentradas em polos de apoio onde os estudantes assistem às aulas transmitidas ao vivo ou pré-gravadas, com maior ou menor interação, dependendo das tecnologias disponíveis.

A estrutura inclui tutores presenciais que atuam nos polos e tutores a distância, que auxiliam os professores e são tutores de conteúdo. Coordenadores e professores eventualmente visitam os polos para aulas presenciais e atividades de laboratório assistidas.

Os polos localizam-se em cidades pequenas e médias, em comunidades rurais e em locais onde os recursos de comunicação são reduzidos, em função da grande disparidade de inclusão digital ainda existente no país. Dessa disparidade resulta a grande variação das tecnologias utilizadas pelos cursos, bem como adaptações e inovações em torno do modelo básico, produzindo um sistema rico de inovações e experimentos metodológicos.

O programa e-Tec foi criado com a finalidade de "ampliar a oferta e democratizar o acesso a cursos técnicos de nível médio, públicos e gratuitos no País" (BRASIL, 2015). Para cumprir com as suas finalidades, o decreto que criou o sistema relaciona os seguintes objetivos:

I - expandir e democratizar a oferta de cursos técnicos de nível médio, especialmente para o interior do país e para a periferia das áreas metropolitanas; 
II - permitir a capacitação profissional inicial e continuada para os estudantes matriculados e para os egressos do Ensino Médio, bem como para a educação de jovens e adultos;

III - contribuir para o ingresso, permanência e conclusão do Ensino Médio pelos jovens e adultos;

IV - permitir, às instituições públicas de ensino profissional, o desenvolvimento de projetos de pesquisa e de metodologias educacionais em educação a distância na área de formação inicial e continuada de professores para a educação profissional técnica de nível médio;

V - promover, junto às instituições públicas de ensino, o desenvolvimento de projetos voltados para a produção de materiais pedagógicos e educacionais para a formação inicial e continuada de docentes para a educação profissional técnica de nível médio;

VI - promover, junto às instituições públicas de ensino, o desenvolvimento de projetos voltados para a produção de materiais pedagógicos e educacionais para estudantes da educação profissional técnica de nível médio;

VII - criar rede nacional de educação profissional nas instituições públicas de ensino, para oferta de educação profissional à distância, em escolas das redes públicas municipais e estaduais; e

VIII - permitir o desenvolvimento de cursos de formação continuada e em serviço de docentes, gestores e técnicos administrativos da educação profissional técnica de nível médio na modalidade de educação a distância.

A partir de sua implantação, o Programa e-Tec, depois Rede e-Tec, foi ampliado, abrangendo cerca de meia centena de cursos ofertados por instituições de todo o país, chegando a milhares de estudantes.

Em 2013 o número de polos que ofertaram cursos foi 841 e, segundo o MEC, teria a meta de receber cerca de 250.000 novas matrículas (BRASIL, 2013).

\section{Implementação dos Cursos no CEFET-MG}


O projeto de EaD promovido pelo CEFET-MG, dentro do Programa Rede e-Tec Brasil, propõe a formação técnica em diversas áreas, tendo como uma de suas iniciativas de formação o curso técnico de Informática para Internet, vinculado ao eixo tecnológico de informação e comunicação. Este curso possui, como foco, uma formação que propicie o atendimento das demandas do ambiente produtivo, que valoriza o desenvolvimento da qualidade nas atividades profissionais, proporcionando integração com rotinas que envolvem processos de trabalho alinhados aos seus respectivos eixos tecnológicos.

Neste contexto, o modelo de EaD aplicado ao curso de Informática para Internet foi organizado da seguinte forma:

- $\quad$ O Curso usa a Internet como meio de interação e disseminação de conteúdo, tendo como plataforma básica o AVEA (Ambiente Virtual de Ensino e Aprendizagem) Moodle;

- $\quad$ Carga horária limite de 1200h, desenvolvidas em 4 módulos semestrais, atendendo à execução de 22 disciplinas;

- Cada módulo contempla até o limite de 6 disciplinas;

- $\quad$ Os módulos permitem uma formação básica, verticalizada, onde o conteúdo desenvolvido em um semestre proporciona os pré-requisitos necessários à continuidade da formação do estudante;

- $\quad$ Os estudantes realizam todas as atividades pelo AVEA;

- Todas as disciplinas devem ofertar o mínimo de $20 \%$ de atividades teóricas e/ou práticas presenciais no período de execução do módulo;

- $\quad$ Estágio obrigatório com o mínimo de 480h;

- $\quad$ O curso é gerado e gerenciado pelo Núcleo de Educação a Distância (NEaD) do CEFET-MG e difundido nos polos. Os polos devem possuir infraestrutura para acesso à internet (laboratório de computadores), ambiente de estudo e biblioteca.

A metodologia de Ensino aplicada no curso tem, por princípio, as questões tratadas por Libâneo (1992), quando enfatiza a importância da relação professor-estudante. Segundo este autor, a interação professor-estudante é um aspecto fundamental na 
organização da situação didática, tendo em vista alcançar os objetivos do processo ensinoaprendizagem: a transmissão e a assimilação de conhecimentos, hábitos e habilidades.

Nesta perspectiva, o curso foi organizado contemplando a existência de:

- Professor Conteudista: que gera todo o conteúdo técnico aplicado à disciplina, proporcionando a criação do caderno didático;

- $\quad$ Professor Formador: que acompanha a disciplina, orientando os momentos de interação com os estudantes e organizando o processo de ensino;

- $\quad$ Tutor a Distância: que atua no apoio ao estudante através da interface no ambiente AVEA;

- Tutor Presencial: que acompanha o estudante no polo, atendendo as dúvidas em relação ao uso do ambiente virtual e na execução das suas atividades;

- Professor Tutor: que acompanha, estimula e orienta as atividades teóricas e práticas, em consonância com os Professores Formadores, promovendo maior interação e participação dos estudantes nas atividades.

No CEFET-MG, as atividades de gestão do curso são realizadas diretamente pelo Coordenador de Curso, já as tarefas de organização da infraestrutura física para proporcionar acesso ao ambiente virtual ficam a cargo do Coordenador de Polo.

Para que o trabalho educativo tenha sucesso, é imprescindível o acompanhamento do processo de aprendizado dos estudantes, uma vez que as turmas apresentam alto grau de heterogeneidade na formação. É pela observação e pela interação que se torna possível conhecer um pouco mais de cada estudante, permitindo a utilização de práticas educativas que melhor atendam às necessidades do grupo.

Para proporcionar o devido desenvolvimento cognitivo e ampliação do conhecimento dos estudantes, buscou-se referência na Metodologia de Unidades Didáticas (MUD) que, conforme Morrison (1931) aponta cinco tipos de aprendizagem nas disciplinas apresentadas:

- disciplinas científicas - como matemática e gramática e as ciências físicas ou sociais, cujo objetivo é ampliar a compreensão e o entendimento da realidade; 
- disciplinas apreciativas - como a literatura e a ética, onde os problemas dos valores e da conduta se destacam;

- disciplinas práticas - promoveriam o ajustamento do estudante aos aspectos materiais de seu ambiente;

- disciplinas artes linguísticas - que envolvem os meios de expressar e de interpretar os pensamentos e sentimentos quer através do vernáculo, até mesmo nas línguas estrangeiras;

- disciplinas práticas puras - é a parte automatizável destas disciplinas, tomando por base o hábito desenvolvido e fixado pela repetição.

Este tipo de metodologia pode ser aplicado em todas as disciplinas, com variantes apropriadas a cada natureza. É aplicável às disciplinas que visem à compreensão, podendo ser seguido, em parte, pelas disciplinas apreciativas. Nas disciplinas que têm por objetivo básico o domínio de habilidades ou técnicas, a MUD torna-se adequada para promover a sistematização de conhecimentos, pois proporciona um método apropriado para consolidar fundamentos teóricos e científicos com o objetivo de proporcionar o devido entendimento das atividades práticas, evitando um mero processo de repetição. Desta forma, a proposta apresentada propõe a realização de práticas que são geradas a partir do entendimento de bases tecnológicas e científicas.

Diante da metodologia de ensino aplicada verificou-se a existência de três fases: diagnose, ensino e verificação. O processo de diagnose envolve a separação dos conhecimentos que se deseja desenvolver com os estudantes; já o processo de ensino abrange o uso de diferentes procedimentos didáticos para proporcionar o aprendizado do conteúdo e, por último, no processo de verificação, utilizam-se os meios para avaliar se o estudante efetivamente apossou-se dos conhecimentos. Estas três fases podem ser repetidas várias vezes, pois têm como principal objetivo a aprendizagem significativa do estudante, e não a simples memorização de dados.

Todo o trabalho é permeado pelo compartilhamento de informações e apoio entre todas as disciplinas, lembrando sempre que uma disciplina pode depender de outra e que o trabalho conjunto e integrado entre os professores possibilita maior e melhor entendimento por parte dos estudantes, sem esquecer a contextualização, onde são necessários objetivos 
mais concretos para que sejam capazes de compreender o que está sendo estudado e, assim, encontrar o caminho para o entendimento e para a construção do conhecimento.

Dentro da proposta estudada verificou-se, também, o uso da Metodologia de Projetos, não aplicável em tempo integral, mas priorizada no processo de contextualização e interdisciplinaridade, proporcionando a teorização na prática.

Os procedimentos didáticos desenvolvidos no âmbito do curso foram dirigidos na promoção da pesquisa, implementação de pequenos projetos, problematização de temas partindo da realidade social e do trabalho de cada estudante, a interpretação e produção de textos relacionados à descrição de fatos e saberes, e leituras de notícias atuais veiculadas na mídia. Faz parte, também do processo proposto, o desenvolvimento de trabalhos em equipe, aulas presenciais e visitas técnicas, além do estágio.

Enfim, toda a prática pedagógica foi integrada e desenvolvida de forma a atender a uma rede de significados, ou seja, voltando-se para a concretização da formação de ser, do saber, do fazer e do conviver deste ser humano que se encontra em nossas mãos. É fundamental o desenvolvimento da capacidade de explicitar o raciocínio, superando as dificuldades que possam emperrar a aprendizagem, atingindo, assim, o sucesso do processo ensino-aprendizagem.

\section{Considerações Finais}

Dentro da perspectiva apresentada, verificou-se que o curso de Informática para Internet ofertado na modalidade EaD, a partir do Programa Rede e-Tec Brasil possui, na sua estrutura organizacional, componentes que são fundamentais para o alcance do sucesso desejado. Entendendo o sucesso como um resultado qualitativo e quantitativo.

Alguns elementos são destacados como essenciais, a saber: a existência do polo que trabalhada como uma unidade de integração e desenvolvimento do trabalho em grupo; a existência do tutor presencial como elemento de apoio e orientador das atividades propostas, o trabalho desenvolvido pelos Professores Conteudistas e Formadores, gerando um conteúdo técnico específico para a disciplina que será lecionada; e a orientação e o 
estímulo gerado aos estudantes pelo trabalho de desenvolvimento de atividades teóricas e práticas realizadas pelo Professor Tutor no polo.

Da mesma forma, as relações existentes entre as disciplinas nos quatro módulos, promovendo pré-requisitos necessários à promoção da verticalização da formação, dentro de um processo gradativo de desenvolvimento de conhecimento e a organização das disciplinas atendendo a metodologia de unidades didáticas e de trabalho por projetos, corroboram para a geração de um ambiente de sucesso no processo de ensino-aprendizagem.

Compreende-se, a partir da experiência com o curso técnico de Informática para Internet na modalidade a distância, que a educação profissional técnica, estimulada pelo Programa Rede e-Tec Brasil, abre um novo caminho, pois amplia as ações de formação profissional já existentes e incentiva a qualificação de profissionais da área educacional, além de permitir a ampliação significativa da oferta de vagas.

Por fim, entende-se que o modelo de construção do curso técnico na modalidade a distância ofertado pelo CEFET-MG cumpre com a sua função social, pois proporciona o desenvolvimento de uma formação de qualidade para os indivíduos que não têm condições de se habilitarem profissionalmente em suas regiões de residência, ou mesmo, de se deslocarem para tal.

\section{Referências}

ABED. Associação Brasileira de Educação a Distância. 2015. Disponível em: <goo.gl/MSOTJ>. Acesso em: 12 ago. 2016.

BRASIL. Decreto № 2.208 de 17 de abril de 1997. Regulamenta o § 2 o do art. 36 e os arts. 39 a 42 da Lei no 9.394, de 20 de dezembro de 1996, que estabelece as diretrizes e bases da educação nacional. Diário Oficial da República Federativa do Brasil, Brasília, DF, 1997. Disponível em: <https://goo.gl/k0ph6h>. Acesso em 30 jul. 2016.

BRASIL. Lei № 7.044 de 18 de outubro de 1982. Altera dispositivos da Lei no 5.692, de 11 de agosto de 1971, referentes a profissionalização do ensino de 20 grau. Diário Oficial da República Federativa do Brasil, Brasília, DF, 1982. Disponível em: <https://goo.gl/cFOSEs $\rangle$. Acesso em 30 jul. 2016.

BRASIL. Lei no 10.973, de 2 de dezembro de 2004. Dispõe sobre incentivos à inovação e à pesquisa científica e tecnológica no ambiente produtivo e dá outras providências. Diário Oficial da República Federativa do Brasil, Brasília, DF, 2004. Disponível em: <https://goo.gl/bHV6fm>. Acesso em: 12 ago. 2016. 
BRASIL. Decreto № 5.800 de $\mathbf{8}$ de junho de 2006. Dispõe sobre o Sistema Universidade Aberta do Brasil - UAB. Diário Oficial da República Federativa do Brasil, Brasília, DF, 2006. Disponível em: <https://goo.gl/X5wQUl>. Acesso em 30 jul. 2016.

BRASIL. Decreto № 6.301 de 12 de dezembro de 2007. Institui o Sistema Escola Técnica Aberta do Brasil - e-Tec Brasil. Diário Oficial da República Federativa do Brasil, Brasília, DF, 2007. Disponível em: <https://goo.gl/1H83l5>. Acesso em 30 jul. 2016.

BRASIL. PROGRAMA NACIONAL DE ACESSO AO ENSINO TÉCNICO E EMPREGO - PRONATEC. Diretoria de integração das redes de educação profissional-SETEC/MEC. Rio de Janeiro. Maio, 2013. Disponivel em: <http://goo.gl/4beJOc>. Acesso em: 12 ago. 2016.

BRASIL. Portal Brasil. 2015. Disponível em: <http://goo.gl/apKbKs>. Acesso em: 23 ago. 2015.

BRITO, C. E. Educação a distancia (EaD) no ensino superior de Moçambique. 2010.

246fls.Tese (Doutorado em Engenharia e Gestão do Conhecimento) - Programa de PósGraduação em Engenharia e Gestão do Conhecimento. Universidade Federal de Santa Catarina, Florianópolis, 2010.

CNCT. Catálogo Nacional de Cursos Técnicos. 2014. Disponível em: <http://goo.gl/8lpzxB $>$. Acesso em: 12 ago. 2016.

CUNHA, L. A. Ensino médio e ensino profissional: da fusão à exclusão. Tecnologia e Cultura, Ano 2, 2: 25-42, jul.-dez., 1998.

CUNHA, L. A. O ensino profissional na irradiação do industrialismo. São Paulo: Unesp, Brasília, DF: Flacso, 2000.

HIJAZI, S. et al. Interactive technology impact on quality distance education. Electronic Journal of e-Learning, v.1, n.1, p.35-44, 2003. Disponível em: 〈http://goo.gl/Gxu5q6>. Acesso em: 12 ago. 2016.

LIBÂNEO, J. C. C. Didática. São Paulo: Cortez, 1992

MORAN, J. M. O que é educação a distância. 2002. Disponível em: <http://goo.gl/qinQHU>. Acesso em: 12 ago. 2016.

MOORE, M.; KEARSLEY, G. Educação a distância: uma visão integrada. São Paulo: Thomson Learning, 2007.

MOORE, M. G; KEARSLEY, G. Distance education: a systems view. Wadsworth Publishing Company, 1996. 
MOREIRA, B. C. M. et al. Gestão acadêmica na educação a distância: desafios e práticas. In: COLÓQUIO INTERNACIONAL SOBRE GESTIÓN UNIVERSITARIA EN AMERIA DEL SUR, 2010, Mar del Plata. Anais... Mar del Plata, dez. 2010.

MORRISON, H.C. The practive of teaching in the secondary school. Chicago. The University of Chicago Press. 1931.

NUNES, I. B. A história da EaD no mundo. In: LITTO, F. M.; FORMIGA, M. M. M. Educação a distância: o estudo da arte. São Paulo: Pearson Education do Brasil, 2009.

VOIGT, E. A ponte sobre o abismo: educação semipresencial como desafio dos novos tempos. Estudos Teológicos, São Leopoldo, v.47, n.2, 2007. Disponível em: <http://goo.gl/FKtBBX>. Acesso em: 12 ago. 2016.

RECEBIDO EM 14 DE AGOSTO DE 2016.

APROVADO EM 31 DE OUTUBRO DE 2016. 